\title{
Comparative analysis of volatile and phenolic composition of alternative wood chips from cherry, acacia and oak for potential use in enology
}

\author{
António M. Jordão ${ }^{1, \text { a }}$, Virginia Lozano ${ }^{2}$, Ana C. Correia ${ }^{1}$, Miriam Ortega-Heras ${ }^{2}$, and María L. González-SanJosé2 \\ ${ }^{1}$ Instituto Politécnico de Viseu (CI\&DETS), Escola Superior Agrária, Ranhados, 3500-606 Viseu, Portugal \\ ${ }^{2}$ Universidade de Burgos, Faculdade de Ciências, Departamento de Biotecnologia e Ciência dos Alimentos, Plaza Misael Bañuelos s/n, \\ 09001 Burgos, Espanha
}

\begin{abstract}
The aim of present work was to investigate the phenolic and volatile composition of cherry, acacia, and oak (from different species) wood chips. By the use of HPLC-DAD 18 different phenolic compounds were detected and quantified while for volatile composition, 33 different compounds were detected by GCMS. In general, wood samples from oak species showed the higher number of phenolic compounds detected, while cherry wood samples showed the lowest levels. In addition, some individual phenolic compounds were detected, specifically in some wood samples, such as robinetin in acacia woods and naringenin in cherry wood. For volatile composition, cherry wood chips samples showed the lowest volatile composition followed by increasing order by acacia, French, Portuguese and American wood chip samples. Oak wood chip samples from American species showed the highest volatile content, as a result of high levels of several specific compounds (furfural, 5-methyfurfural, $\beta$-methyl- $\gamma$-octalactones, guaiacol, vanillin and siringaldehyde).
\end{abstract}

\section{Introduction}

Wine aging with alternative systems consists of adding wood to wine to acquires certain properties recalling wine that is aged in barrels. Pieces of wood of different types (wood origin, size, toasting, and others), are usually used to simulating the aging process in barrels. In addition, a great variety of oak wood pieces for this purpose can be found on the market: chips, cubes, powder, shavings, granulates, blocks or segments and even staves $[1,2]$. It is also important to note that the increased used of these alternatives are mainly related to low investments, similar sensorial results obtained in shorter time and simplicity of use [3]. Their use then spread, particularly in Australia, Chile and Argentina. In Europe, alternative products could not be used until 2006, and only some experimental practices were allowed (EEC 822/87). The EEC regulation No. 1507/2006 of 11 October 2006 modified previous rules by regulating the use of pieces of oak and chestnut for winemaking and the description and presentation of wine undergoing this treatment (EEC). It states that the pieces of oak wood must be exclusively come from the Quercus genus. However, it is important to note that the increasing demand of oak wood caused a remarkable potential increase in costs due to the limited availability of materials. Furthermore, the high demand of oak wood products has also an ecological impact on harvesting of oak trees in forest where the replacement of trees is not guaranteed. Thus, the use of potential alternative woods, such as acacia and cherry, may be an interesting option for use in wine aging process. In addition, there are a scare detailed information about the acacia and

a e-mail: antoniojordao@esav.ipv.pt cherry woods composition and also a comparison with the composition of these wood species with French, American, Portuguese and Spanish oak woods. Due to this, the aim of present work was to investigate the phenolic and volatile composition of acacia and cherry and make a comparative analysis with oak wood chips from different species.

\section{Material and methods}

\subsection{Material}

The samples used in this study were oak wood chips from Quercus pyrenaica L. (Portuguese oak), Quercus alba L. (American oak) and Quercus petraea L. (French oak) species. For alternative wood species, Robinia pseudoacacia (acacia wood) and Prunus avium (cherry wood) were used. All wood chips samples presented a dimension of $\pm 8 \mathrm{~mm}$, a medium toasting intensity and were provided by AEB Bioquímica Portuguesa (Viseu, Portugal). In order to study the volatile and phenolic composition of the different alternative woods, the wood chips samples $(4 \mathrm{~g} / \mathrm{L})$ were placed in $500 \mathrm{~mL}$ of model wine solutions (12\%; $\mathrm{pH} 3.5)$ for 30 days. All extraction assays were done in duplicate, placed in the dark and agitated daily (under magnetic stirring for $5 \mathrm{~min}$ ).

\subsection{Methods}

For individual phenolic compounds an analysis by the use of HPLC-DAD following the methodologies described by Pérez et al. [4] and by Viriot et al. [5] were used. In addition, for individual volatile composition a GCMS technique was applied following the chromatography 
Table 1. Individual phenolic compounds quantified $(\mathrm{mg} / \mathrm{L})$ in cherry, acacia and different oak wood chips extracted in model wine solutions for 30 days.

\begin{tabular}{|c|c|c|c|c|c|}
\hline \multirow{2}{*}{ Phenolic compounds } & \multirow[b]{2}{*}{ Cherry } & \multirow[b]{2}{*}{ Acacia } & \multicolumn{3}{|c|}{ Oak wood } \\
\hline & & & French & American & Portuguese \\
\hline Protocatechuic aldehyde $^{(1)}$ & nd & $1.40 \pm 0.02$ & nd & nd & nd \\
\hline Gallic acid & nd & nd & $1.25 \pm 0.02$ & nd & $1.44 \pm 0.07$ \\
\hline Vanillic acid & nd & nd & $0.14 \pm 0.02$ & $0.33 \pm 0.01$ & $0.128 \pm 0.003$ \\
\hline Syringic acid & nd & nd & $0.44 \pm 0.07$ & $0.83 \pm 0.01$ & $0.22 \pm 0.02$ \\
\hline$(+)$-Catechin & $18.51 \pm 0.08$ & nd & nd & nd & nd \\
\hline Robinetin $^{(2)}$ & nd & $118.94 \pm 0.28$ & nd & nd & nd \\
\hline Benzaldehyde & nd & nd & $11.44 \pm 0.54$ & $12.68 \pm 1.08$ & $7.93 \pm 0.78$ \\
\hline Fustin $^{(2)}$ & nd & $0.86 \pm 0.01$ & nd & nd & nd \\
\hline Butin $^{(2)}$ & nd & $3.52 \pm 0.01$ & nd & nd & nd \\
\hline Robtin ${ }^{(2)}$ & nd & $3.05 \pm 0.04$ & nd & nd & nd \\
\hline$p$-Coumaric acid & $172.5 \pm 11.7$ & nd & $153.4 \pm 1.6$ & nd & $84.3 \pm 1.8$ \\
\hline Coniferaldehyde ${ }^{(3)}$ & nd & nd & $1.42 \pm 0.27$ & $1.35 \pm 0.02$ & $0.90 \pm 0.02$ \\
\hline Syringaldehyde ${ }^{(4)}$ & nd & nd & $0.109 \pm 0.001$ & nd & $0.11 \pm 0.01$ \\
\hline Quercetin & nd & nd & $5.45 \pm 1.12$ & $5.49 \pm 0.06$ & $2.48 \pm 0.05$ \\
\hline Naringenin & $5.54 \pm 0.06$ & nd & nd & nd & nd \\
\hline Vescalagin $^{(5)}$ & nd & nd & $19.21 \pm 1.96$ & $6.21 \pm 1.21$ & $25.74 \pm 1.54$ \\
\hline Castalagin $^{(5)}$ & nd & nd & $24.97 \pm 2.87$ & $5.43 \pm 0.87$ & $32.45 \pm 2.96$ \\
\hline Ellagic acid & $0.72 \pm 0.03$ & $0.049 \pm 0.004$ & $3.49 \pm 0.12$ & $1.17 \pm 0.05$ & $4.91 \pm 0.27$ \\
\hline Total & $197.27^{\mathrm{A}(6)}$ & $127.81^{\mathrm{B}}$ & $221.31^{\mathrm{C}}$ & $33.49^{D}$ & $160.60^{\mathrm{E}}$ \\
\hline
\end{tabular}

conditions described by Mihnea et al. [6]. All analyses were done in triplicate.

\section{Results and discussion}

\subsection{Individual phenolic composition}

Individual phenolic compounds from the different alternative wood chips from cherry, acacia and 3 different oak species are shown in Table 1. A total of 18 different phenolic compounds were detected and quantified.

According to the results showed in Table 1, cherry wood extract samples revealed the lowest number of individual phenols quantified (only (+)-catechin, $p$-coumaric acid, naringenin and ellagic acid). In addition, it is important to noted that it was only in cherry wood extracts that was possible detected $(+)$-catechin $(18.51 \mathrm{mg} / \mathrm{L})$ and naringenin $(5.54 \mathrm{mg} / \mathrm{L})$. These results are in agreement with previous findings quantified in toasted cherry wood samples [7].

Ellagic acid and $p$-coumaric acid were the only 2 phenolic compounds which have been detected in a common way in cherry and oak wood extracts. However, according to Fernandez de Simon et al. [8] it is possible to detected other phenolic compounds, namely volatile phenols, phenolic aldehydes and lignin derivatives.

For acacia wood extracts, several phenolic compounds, such as, protocatechuic aldehyde $(1.40 \mathrm{mg} / \mathrm{L})$, robinetin $(118.94 \mathrm{mg} / \mathrm{L})$, fustin $(0.86 \mathrm{mg} / \mathrm{L})$, butin $(3.52 \mathrm{mg} / \mathrm{L})$ and robtin $(3.05 \mathrm{mg} / \mathrm{L})$ were detected specifically in the extracts of this wood specie. For the different oak wood species studied, the individual phenolic compounds detected were mainly low molecular weight phenolic compounds, resulting primarily from thermodegradation of lignin during the toasting process (for example, syringaldehyde, coniferaldehyde and vanillic acid). In addition, French and Portuguese oak wood extract samples showed higher individual phenolic content than American oak wood extract samples, confirming previously results obtained by other authors $[2,9]$.

By analyzing of Table 1, it is also possible to demonstrate that the oak wood extract samples from Quercus petraea (French oak) showed significantly higher total phenolic compounds $(221.31 \mathrm{mg} / \mathrm{L})$ than samples from the other wood species studied, while oak wood extract samples from Quercus Alba (American oak) showed the lowest total values $(33.49 \mathrm{mg} / \mathrm{L})$.

Finally, it was also clear that cherry and acacia wood extract samples showed intermediate values (197.27 and $127.81 \mathrm{mg} / \mathrm{L}$, respectively).

\subsection{Individual volatile composition}

Table 2 shows the volatile compounds identified and semi quantified (using the chromatographic peak area in arbitrary units) for the different wood species studied. Thirty three different volatile compounds were identified. 
Table 2. Average peak area ${ }^{(1)}$ of individual volatile compounds quantified in cherry, acacia and different oak wood chips extracted in model wine solutions for 30 days.

\begin{tabular}{|c|c|c|c|c|c|}
\hline \multirow{2}{*}{ Volatile compounds } & \multirow[b]{2}{*}{ Cherry } & \multirow[b]{2}{*}{ Acacia } & \multicolumn{3}{|c|}{ Oak wood } \\
\hline & & & French & American & Portuguese \\
\hline D-limonene & $2.67 \times 10^{-3}$ & nd & $1.14 \times 10^{-3}$ & nd & $3.84 \times 10^{-3}$ \\
\hline Ethyl hexanoate & $2.21 \times 10^{-3}$ & nd & nd & nd & nd \\
\hline 2-Octanone & $50.21 \times 10^{-3}$ & $16.4 \times 10^{-3}$ & $17.45 \times 10^{-3}$ & $9.62 \times 10^{5}$ & $40.92 \times 10^{-3}$ \\
\hline 2-Butoxyethanol & $8.72 \times 10^{-3}$ & nd & nd & nd & nd \\
\hline Ethyl octanoate & $4.59 \times 10^{-3}$ & $8.0 \times 10^{-3}$ & $6.31 \times 10^{-3}$ & nd & $2.30 \times 10^{-3}$ \\
\hline Heptanol & $1.96 \times 10^{-3}$ & $1.70 \times 10^{-3}$ & $1.85 \times 10^{-3}$ & nd & $0.32 \times 10^{-3}$ \\
\hline Furfural & $3.24 \times 10^{-3}$ & $13.70 \times 10^{-3}$ & $134.14 \times 10^{-3}$ & $20.69 \times 10^{6}$ & $5.75 \times 10^{-3}$ \\
\hline 2-Nonenal & $0.86 \times 10^{-3}$ & nd & $1.63 \times 10^{-3}$ & nd & $8.53 \times 10^{-3}$ \\
\hline 5-Methylfurfural & $1.54 \times 10^{-3}$ & $8.20 \times 10^{-3}$ & $93.42 \times 10^{-3}$ & $10.65 \times 10^{6}$ & $75.53 \times 10^{-3}$ \\
\hline 2-Furancarboxylic acid ethyl ester & $1.89 \times 10^{-3}$ & nd & $1.74 \times 10^{-3}$ & nd & $1.84 \times 10^{-3}$ \\
\hline Acetophenone & $39.10 \times 10^{-3}$ & $1.80 \times 10^{-3}$ & $1.58 \times 10^{-3}$ & nd & $2.53 \times 10^{-3}$ \\
\hline Ethyl benzoate & $52.58 \times 10^{-3}$ & nd & nd & nd & $1.03 \times 10^{-3}$ \\
\hline 4-Phenyl-2-butanone & $10.0 \times 10^{-3}$ & nd & nd & nd & nd \\
\hline 2-methoxyphenol (guaiacol) & $8.22 \times 10^{-3}$ & $12.8 \times 10^{-3}$ & $4.20 \times 10^{-3}$ & $12.52 \times 10^{5}$ & $4.12 \times 10^{-3}$ \\
\hline$\beta$-methyl- $\gamma$-octalactones & $18.12 \times 10^{-3}$ & $16.5 \times 10^{-3}$ & $119.66 \times 10^{-3}$ & $199.83 \times 10^{5}$ & $521.8 \times 10^{-3}$ \\
\hline 2-Phenylethanol & $1.50 \times 10^{-3}$ & $1.52 \times 10^{-3}$ & nd & $99.72 \times 10^{4}$ & $0.71 \times 10^{-3}$ \\
\hline 1,3-Benzothiazole & $2.42 \times 10^{-3}$ & $1.9 \times 10^{-3}$ & $3.29 \times 10^{-3}$ & $63.85 \times 10^{4}$ & $4.12 \times 10^{-3}$ \\
\hline $\begin{array}{l}\text { 4-Ethyl-2-methoxy-phenol } \\
\text { (4-ethylguaiacol) }\end{array}$ & $0.55 \times 10^{-3}$ & $0.40 \times 10^{-3}$ & $1.89 \times 10^{-3}$ & $37.84 \times 10^{4}$ & $1.38 \times 10^{-3}$ \\
\hline trans-Cinnamaldehyde & $5.17 \times 10^{-3}$ & $4.10 \times 10^{-3}$ & $0.33 \times 10^{-3}$ & nd & $1.0 \times 10^{-3}$ \\
\hline trans-Benzalacetone & $15.59 \times 10^{-3}$ & $1.0 \times 10^{-3}$ & nd & nd & nd \\
\hline Ethyl cinnamate & $1.77 \times 10^{-3}$ & nd & nd & nd & nd \\
\hline Eugenol & $1.29 \times 10^{-3}$ & $0.60 \times 10^{-3}$ & $3.99 \times 10^{-3}$ & $59.39 \times 10^{4}$ & $12.01 \times 10^{-3}$ \\
\hline 5-Acetoxymethyl-2-furaldehyde & nd & $1.90 \times 10^{-3}$ & $10.68 \times 10^{-3}$ & $25.0 \times 10^{5}$ & $5.01 \times 10^{-3}$ \\
\hline 2-Methyl-5-(1-methylethyl)-phenol & $4.19 \times 10^{-3}$ & nd & nd & nd & nd \\
\hline Syringol & $0.26 \times 10^{-3}$ & $3.50 \times 10^{-3}$ & $5.56 \times 10^{-3}$ & $23.73 \times 10^{5}$ & $2.26 \times 10^{-3}$ \\
\hline 4-(1,1-Dimethylethyl)-phenol & $2.34 \times 10^{-3}$ & $1.40 \times 10^{-3}$ & nd & nd & $1.21 \times 10^{-3}$ \\
\hline 2,4-Ditert-butylphenol & $32.65 \times 10^{-3}$ & $26.60 \times 10^{-3}$ & $12.0 \times 10^{-3}$ & $15.90 \times 10^{5}$ & $29.73 \times 10^{-3}$ \\
\hline 3,4-Dimethoxybenzaldehyde & $1.12 \times 10^{-3}$ & $1.11 \times 10^{-3}$ & nd & nd & nd \\
\hline Benzoic acid & nd & nd & nd & $16.83 \times 10^{6}$ & nd \\
\hline $\begin{array}{l}\text { 8-Hydroxy-3-methyl-3,4- } \\
\text { dihydroisochromen-1-one }\end{array}$ & $2.06 \times 10^{-3}$ & nd & nd & nd & nd \\
\hline 3,4,5-Trimethoxybenzaldehyde & $0.71 \times 10^{-3}$ & $1.0 \times 10^{-3}$ & nd & nd & nd \\
\hline Vanillin & $1.64 \times 10^{-3}$ & $120.8 \times 10^{-3}$ & $71.77 \times 10^{-3}$ & $31.75 \times 10^{6}$ & $169.45 \times 10^{-3}$ \\
\hline Syringaldehyde & $2.49 \times 10^{-3}$ & $200.0 \times 10^{-3}$ & $68.69 \times 10^{-3}$ & $39.05 \times 10^{6}$ & $71.41 \times 10^{-3}$ \\
\hline Total average peak area ${ }^{(2)}$ & $28.16 \times 10^{-2 A}$ & $44.50 \times 10^{-2 B}$ & $56.13 \times 10^{-2 B}$ & $150.26 \times 10^{6 \mathrm{C}}$ & $1.06^{\mathrm{D}}$ \\
\hline
\end{tabular}

${ }^{(1)}$ Values expressed in relative peak area in relation of internal standard; nd - not detected.

${ }^{(2)}$ Values showing the same letter are not significantly different (Tukey, $p<0.05$ ).

From the total average peak area of the volatile compounds identified, it is concluded that American oak wood chips (Quercus alba) released significantly more volatile compounds (a total average peak area of $150.26 \times$ $10^{6}$ ) than the other wood chip species studied.

However, American oak wood chips showed the lowest number of compounds identified (15 different volatile compounds). The high level of total average peak area quantified in American wood chip samples was a consequence of high average peak area amounts of several specific compounds, namely, furfural, 5-methyfurfural, $\beta$-methyl- $\gamma$-octalactones, guaiacol, Benzoic acid, vanillin and siringaldehyde. These compounds are regarded as the main source of the characteristic oak aroma of woodaged wines [10]. In addition, for example the $\beta$-methyl$\gamma$-octalactones (oak lactones) are the most interesting 
organoleptic components of the wood because of their very low odor thresholds [11].

Cherry wood chip samples showed the lowest total average peak area $\left(28.16 \times 10^{-2}\right)$ followed in increasing order by acacia $\left(44.50 \times 10^{-2}\right)$, French $\left(56.13 \times 10^{-2}\right)$ and Portuguese (1.06) wood chip samples. The results also showed that only 2 of the compounds identified (5acetoxymethyl-2-furaldehyde and benzoic acid) were not detected in cherry wood chip samples while for acacia wood chip samples 11 of the compounds identified in the other wood species were not detected (D-limonene, ethyl hexanoate, 2-butoxyethanol, 2-nonenal, 2-Furancarboxylic acid ethyl ester, ethyl benzoate, 4-phenyl-2-butanone, ethyl cinnamate, 2-methyl-5-(1-methylethyl)-phenol, benzoic acid and 8-hydroxy-3-methyl-3,4-dihydroisochromen-1one).

For cherry wood extracts, several volatile compounds (ethyl hexanoate, 2-butoxyethanol, 4-phenyl-2-butanone, ethyl cinnamate, 2-methyl-5-(1-methylethyl)-phenol and 8-hydroxy-3-methyl-3,4-dihydroisochromen-1-one) were detected specifically only in the extracts of this wood specie. In addition, benzoic acid it was only detected in American wood chip samples. Although benzoic acid was only detected in oak wood chip extract samples from American specie (Quercus alba), it has also been detected by other authors [12] in wood chips from cherry wood. However, in chip extracts from cherry wood high levels of ethyl benzoate was found which to explain the higher levels of this compound found by other authors in vinegars obtained by acetification in barrels of cherry wood, as well as in wines aged in cherry wood barrels $[8,13]$.

In a quantitative point of view, ethyl benzoate, 2-octanone and acetophenone were the predominant volatile compounds identified in cherry wood chip extracts (average peak area of $52.58 \times 10^{-3}, 50.21 \times 10^{-3}$ and $39.10 \times 10^{-3}$, respectively) while for acacia wood chip extracts, syringaldehyde and vanillin (average peak area of $200.0 \times 10^{-3}$ and $120.80 \times 10^{-3}$, respectively) were the most prominent compounds. It is important to note that acacia showed higher syringaldehyde and vanillin content than the oak wood chip extracts from Quercus petraea (French oak) and Quercus pyrenaica (Portuguese oak). However, syringaldehyde it was not detected by the use of HPLC analysis in acacia wood extract chip samples. Probably the HPLC methodology used, especially the analytical conditions didn't allow the detection of this specific compound.

\section{Conclusions}

In this study, it became evident that the botanical species studied had a significant influence on the phenolic and volatile composition of the different wood chip extracts analyzed. In fact, the physical properties and the structure of different wood species, such as the proportion of latewood to earlywood and the abundance of fibers, may influence the extraction of compounds into the wine, without going deeper into the natural variability of wood.

The qualitative differences in the phenolic and volatile profiles allow for identifying significantly differences between cherry and acacia wood extract samples in relation to different oak wood extract samples.

In addition, further studies on different toasting intensities and/or different wood origin would be necessary for a better understanding of the influence that especially non oak woods (such as acacia and cherry woods) can have on the quality of aged wines.

António M. Jordão - This work is partially financed by national funds through FCT - Fundação para a Ciência e Tecnologia, I.P., under the project UID/Multi/04016/2016. Furthermore we would like to thank the IPV- CI\&DETS for their support.

\section{References}

[1] M. Del Álamo, Rev. Oenolog. 122, 21-26 (2007)

[2] A.M. Jordão, A.C. Correia, R. Del Campo, M.L. González-SanJosé, Eur. Food Res. Technol. 235, 817-825 (2012)

[3] B. Fernández de Simón, E. Cadahía, M. Del Álamo, I. Nevares, J. Agric. Food Chem. 57, 3217-3227 (2009)

[4] S. Pérez, M. Ortega-Heras, E. Cano, J. Agric. Food Chem. 56, 11560-11570 (2008)

[5] C. Viriot, A. Scalbert, C.L.M. Hervé du Penhoat, M. Moutounet, Phytochemistry, 36, 1253-1260 (1994)

[6] M. Mihnea, M.L. González-SanJosé, M. OrtegaHeras, S. Pérez-Magariño, Food Sci. Technol. 64, 32-41 (2015)

[7] M. Sanz, E. Cadahía, E. Esteruelas, A.M. Muñoz, B. Fernández de Simón, T. Hernández, I. Estrella, J. Agric. Food Chem. 58, 4907-4914 (2010)

[8] B. Fernández de Simón, J. Martínez, M. Sanz, E. Cadahía, E. Esteruelas, A.M. Muñoz, Food Chem. 147, 346-356 (2014)

[9] A.M. Jordão, J.M. Ricardo-da-Silva, O. Laureano, Hollforschung, 61, 155-160 (2007)

[10] M.S. Pérez-Coello, J. Sanz, M.D. Cabezudo, Chromatographia, 47, 427-432 (1998)

[11] P. Chatonnet, D. Dubourdieu, J.N. Boidron, Sci. Aliment. 12, 665-685 (1992)

[12] B. Fernández de Simón, M. Sanz, E. Cadahía, E. Esteruelas, A.M. Muñoz, J. Mass Spectrom. 49, 353-370 (2014)

[13] A.B. Cerezo, W. Tesfaye, M.J. Torija, E. Mateo, C. Garcia-Parrilla, A.M. Troncoso, Food Chem. 109, 606-615 (2008) 